\title{
Article \\ A Multiband Antenna Stacked with Novel Metamaterial SCSRR and CSSRR for WiMAX/WLAN Applications
}

\author{
Rajiv Mohan David ${ }^{1}\left(\mathbb{D}\right.$, Mohammad Saadh AW ${ }^{2}$, Tanweer Ali ${ }^{1, *(\mathbb{D})}$ and Pradeep Kumar ${ }^{3, * \mathbb{C}}$ \\ 1 Department of Electronics and Communication, Manipal Institute of Technology, Manipal Academy of \\ Higher Education, Manipal, Karnataka 567104, India; rajiv.md@manipal.edu \\ 2 School of Electronics, Vellore Institute of Technology, Vellore 632014, India; saadh.mohammad@gmail.com \\ 3 Discipline of Electrical, Electronic and Computer Engineering, University of KwaZulu-Natal, \\ Durban 4041, South Africa \\ * Correspondence: tanweer.ali@manipal.edu (T.A.); pkumar_123@yahoo.com (P.K.)
}

Citation: David, R.M.; AW, M.S.; Ali,

T.; Kumar, P. A Multiband Antenna Stacked with Novel Metamaterial SCSRR and CSSRR for WiMAX/ WLAN Applications. Micromachines 2021, 12, 113. https://doi.org/ $10.3390 / \mathrm{mi1} 2020113$

Academic Editors: Davide Rocco and Paulo Mendes

Received: 3 December 2020

Accepted: 19 January 2021

Published: 22 January 2021

Publisher's Note: MDPI stays neutral with regard to jurisdictional claims in published maps and institutional affiliations.

Copyright: (c) 2021 by the authors. Licensee MDPI, Basel, Switzerland. This article is an open access article distributed under the terms and conditions of the Creative Commons Attribution (CC BY) license (https:// creativecommons.org/licenses/by/ $4.0 /)$.

\begin{abstract}
This paper presents an innovative method for the design of a triple band meta-mode antenna. This unique design of antenna finds application in a particular frequency band of WLAN and WiMAX. This antenna comprises of a square complimentary split ring resonator (SCSRR), a coaxial feed, and two symmetrical comb shaped split ring resonators (CSSRR). The metamaterial unit cell SCSRR independently gains control in the band range 3.15-3.25 GHz (WiMAX), whereas two symmetrical CSSRR unit cell controls the band in the ranges $3.91-4.01 \mathrm{GHz}$ and $5.79-5.94 \mathrm{GHz}$ (WLAN). This design methodology and the study of the suggested unit cells structure are reviewed in classical waveguide medium theory. The antenna has a miniaturized size of only $0.213 \lambda_{0} \times 0.192 \lambda_{0}$ $\times 0.0271 \lambda_{0}\left(20 \times 18 \times 2.54 \mathrm{~mm}^{3}\right.$, where $\lambda_{0}$ is the free space wavelength at $\left.3.2 \mathrm{GHz}\right)$. The detailed dimension analysis of the proposed antenna and its radiation efficiency are also presented in this paper. All the necessary simulations are carried out in High Frequency Structure Simulator (HFSS) 13.0 tool.
\end{abstract}

Keywords: CSSRR; metamaterial; permittivity; permeability; SCSRR

\section{Introduction}

Currently, wireless communication networks employing metamaterial technology are witnessing unprecedented development. Metamaterials are artificially structured media comprising of dielectric inclusions that can be engineered to exhibit peculiar electromagnetic properties [1-4]. These materials have been found to have significant advantages in various field of technology [5]. One such new category is the metamaterial formed by depositing metal structures on dielectric substrates. Subsequently, rather than the composition, the structure of the metamaterial decides its physical property. Left hand medium (LHM) materials investigated by Veselago in 1968 exhibit negative permittivity and permeability through magnetic, electric, and phase triplet vectors [6]. LHM materials are formed by electromagnetic wave propagation due to the parallel and opposite directionality nature of phase and group velocity to the pointing vector, and thus are unavailable in nature. Negative refractive index materials can be used for terahertz applications as demonstrated by Pendry [7].

An electromagnetic metamaterial is not available naturally, and thus is defined as artificially composed uniform structure, wherein the average cell size $p$ should be much smaller than the guided wavelength $\lambda_{\mathrm{g}}\left(p<<\lambda_{\mathrm{g}}\right)$. This condition is maintained to ensure that the scattering or diffraction is mainly controlled by the refractive process after the prorogation of the wave in metamaterial medium [8]. Metamaterials are mainly used to enhance the system performance and antenna parameters such as gain, bandwidth, efficiency, and return loss. Additionally, these artificially created structures also find applications in microwave and terahertz to construct devices such as integrated sensors, 
filters, and more $[9,10]$. The use of metamaterial antenna in improving the performance of the antenna is continuing to evolve rapidly in the present times [11-13]. Metamaterials have been found to be attractive candidates for achieving multiband operation due to their exotic properties such as negative refractive index and the possibility of tailoring permittivity and permeability. In addition to this, the near field boundary conditions of the metamaterial could be altered to achieve a compact size while retaining better radiation performance.

\section{Literature Review}

The literature reports several works on metamaterial based multiband antennas [14-20]. Amani et al. [14] proposed a CPW-fed composite right/left-handed resonant antenna. Although good impedance matching was achieved, lower gain of $-0.5 \mathrm{~dB}$ and total efficiency of $70 \%$ was reported. A microstrip fed monopole antenna was designed by Huang et al. [15]; metamaterial inspired reactive loading and L shaped slots were practically used for achieving multiband operation. It was observed that the antenna dimension had large area of $40 \times 45 \mathrm{~mm}^{2}$. Similarly, a multiband antenna of dimensions $20 \times 30 \mathrm{~mm}^{2}$ was proposed by Yu et al. [16]; multiband operation was achieved by employing complimentary split ring resonators. However, the independent control over the achieved band was not possible. A dual antenna loaded with meandered line and square split ring resonator (SRR) was proposed in [17]. However, the antenna has a relatively larger size of $20 \times 22 \mathrm{~mm}^{2}$ and the overall antenna structure tends to be complex. Aznabet et al. [18] proposed a large sized $30 \times 22 \mathrm{~mm}^{2}$ metamaterial antenna just to operate at single band. The metamaterial unit cell property was not discussed and verified. A composite right/left-handed (CRLH) single-layer metamaterial antenna based on the T-junction discontinuity with a considerable size of $20 \times 20 \mathrm{~mm}^{2}$ was presented in [19]. Although the antenna operated at triple band, a negative gain of around $-0.5 \mathrm{dBi}$ was observed at the lower resonance. Also, the used structure tends to be complex in nature. Similarly, three zeroth order resonator (ZOR) cells-based metamaterial antenna was proposed in [20] for dual band operations. However, the antenna has a large size of $42 \times 50 \mathrm{~mm}^{2}$ with negative gain of $-1.5 \mathrm{dBi}$ at the lowest operating band.

In our investigations, a new meta-mode multiband antenna is presented. The novelty of the work lies in the proposed metamaterial unit cell which is tuned in such a way that each individual unit cell solely controls a particular resonance frequency of the antenna. This feature of the antenna makes it distinguishable with the other multiband metamaterial antennas available in literature. The other main advantages of the proposed antenna are that it provides high miniaturization (i.e., very compact size) and simple and planar configuration with high radiation efficiency and stable radiation pattern as compared to the antenna presented in Table 2 . The proposed design consists of a radiator which includes two metamaterial unit cells, i.e., square complimentary split ring resonator (SCSRR) and two symmetrical comb shaped split ring resonator (CSSRR). SCSRR controls the band at $5.9 \mathrm{GHz}$, whereas CSSRR controls the band at 3.2 and $4 \mathrm{GHz}$, respectively. The metamaterial unit cell and its parameters extraction such as effective permittivity, permeability, and refractive index are studied in detail with the help of waveguide medium environment. Various studies such as split gap effect of unit cell, loading of each unit cell individually, and current distribution are also analyzed. Parametric investigations are discussed to finalize the design dimension of the antenna. The entire simulations of the antenna and metamaterial unit cell is carried out in a High frequency Structure Simulator (HFSS) v.13.0 tool.

\section{Antenna Layout and Design}

Figure 1 describes the design evolution of the suggested metamaterial antenna consisting of a rectangular stub loaded with SCSRR as the radiating patch. Antenna 2 consists of two symmetrical CSSRR along with configuration of Antenna 1. It is observed in Figure 1a that the design is on RT Duroid 6006 substrate with $\varepsilon_{\mathrm{r}}=6.15$, height $=2.54 \mathrm{~mm}$ and loss 
tangent $=0.0019$. The simulated S11 results of the antennas presented inFigure $1 \mathrm{a}$ is given in Figure 1b. The antenna structures shown in Figure 1a uses Finite Element Method (FEM) method with the simulation and optimization performed on HFSS) 13.0 version. Initially Antenna 1 is designed to produce resonance at $5.8 \mathrm{GHz}(\mathrm{WLAN})$ with $\left|\mathrm{S}_{11}\right|<-10 \mathrm{~dB}$ bandwidth ranging from 5.45-6.05 GHz (Figure 1b). However, we can see that the designed Antenna 1 has the disadvantage of single band of operation.

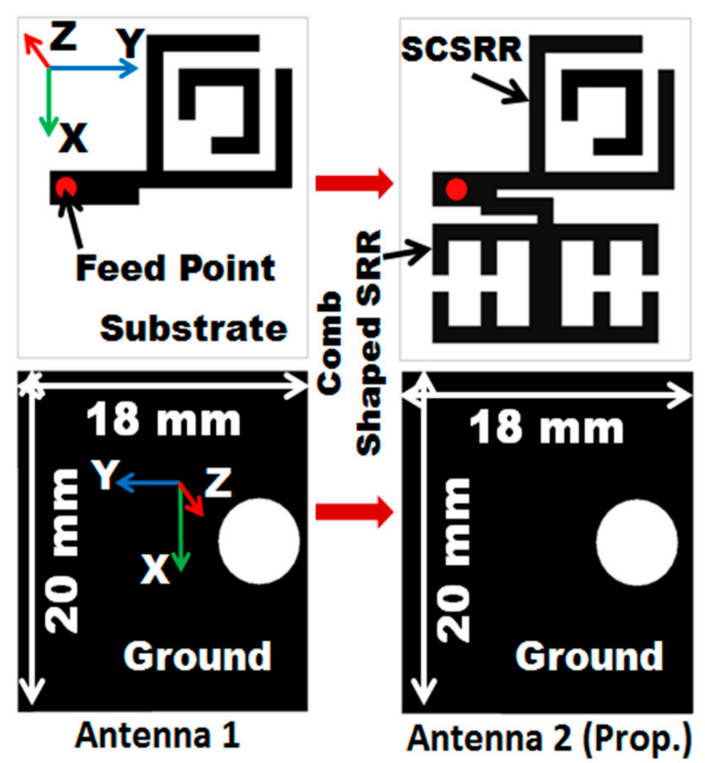

(a)

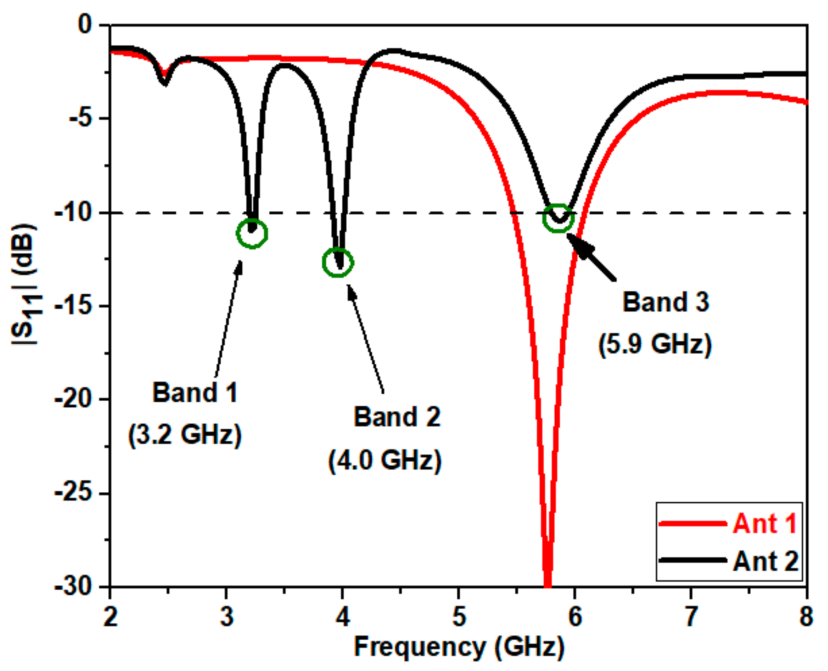

(b)

Figure 1. Proposed antenna design evolution steps (a) Antenna 1 loaded with square complimentary split ring resonator (SCSRR) and (b) Antenna 2 (Prop.) loaded with symmetrical comb shaped split ring resonators (CSSRR) and SCSRR.

In order to get additional operating bands, two symmetrical CSSRR metamaterial unit cells are introduced in the design as depicted in configuration Antenna 2 of Figure 1a. It is apparent that by the inclusion of metamaterial unit cells, the solenoid current is activated along with magnetic field fluctuations resulting in magnetic response from the conductor. This resultant effect makes the antenna to further resonate at 3.2 (WiMAX) and $4 \mathrm{GHz}$ (WLAN) frequency bands.

Figure 2 illustrates the detailed geometry of metamaterial Antenna 2. It is evident that this proposed configuration has the advantage of a simple structure with very compact 
dimension along with triple useful band of operations. It is observed that this antenna is comprised of a radiating patch loaded with SCSRR and two symmetrical CSSRR which are energized by a $50 \Omega$ coaxial feed. To obtain better performance some of the key parameters are adjusted, and the optimized dimension parameters $(\mathrm{mm})$ of the antenna are given in Table 1.

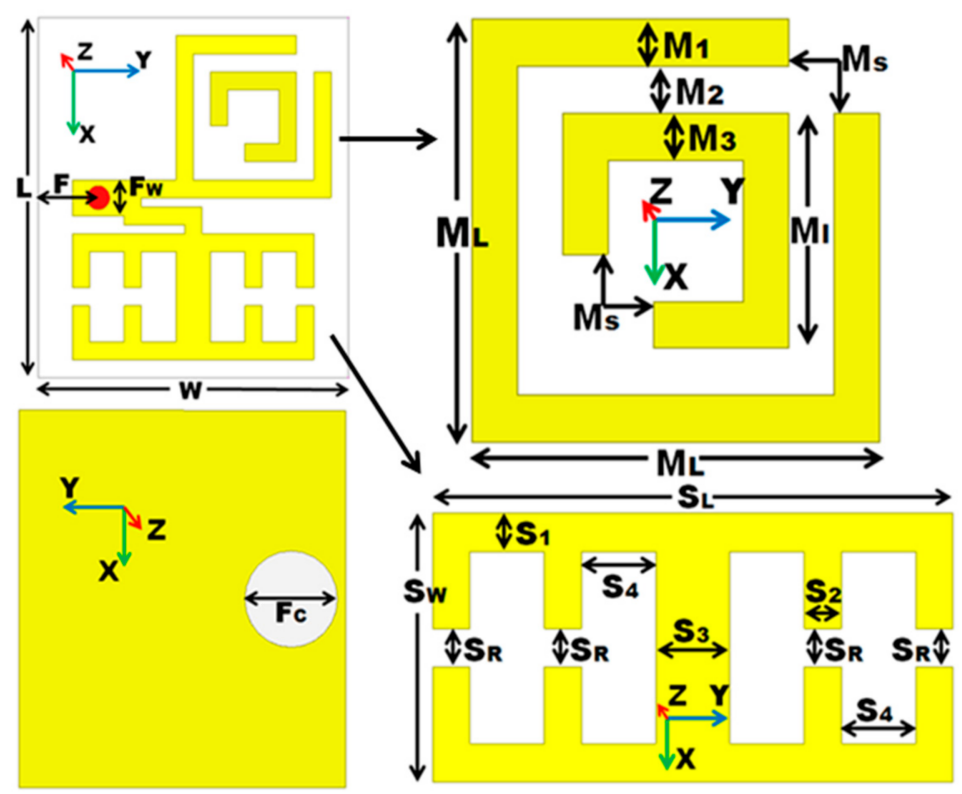

Figure 2. Detailed dimension layout of the proposed antenna.

Table 1. Optimized final dimension of the proposed metamaterial antenna.

\begin{tabular}{cc}
\hline Parameters & Dimension $(\mathbf{m m})$ \\
\hline $\mathrm{L}_{\mathrm{W}}$ & 20 \\
$\mathrm{~F}$ & 18 \\
$\mathrm{~F}_{\mathrm{W}}$ & 3.5 \\
$\mathrm{M}_{\mathrm{L}}$ & 2 \\
$\mathrm{M}_{1}$ & 9 \\
$\mathrm{M}_{\mathrm{S}}$ & 5 \\
$\mathrm{~F}_{\mathrm{C}}$ & 2 \\
$\mathrm{M}=\mathrm{M}_{2}=\mathrm{M}_{3}=\mathrm{S}_{1}=\mathrm{S}_{2}=\mathrm{S}_{\mathrm{R}}$ & 5.1 \\
$\mathrm{~S}_{\mathrm{L}}$ & 1 \\
$\mathrm{~S}_{\mathrm{W}}$ & 14 \\
$\mathrm{~S}_{3}=\mathrm{S}_{4}$ & 7 \\
\end{tabular}

\section{Parameters Extraction of Metamaterial Unit Cell Using Waveguide Medium}

Two of these symmetrical unit cell CSSRR are modeled using metallic resonators and thereby etching a bifurcated gap in the opposing sides, resulting in the desired stop band phenomenon as depicted in Figure 3a. The main advantage of utilizing CSRR metamaterial unit cell is to get multiband operation. This unit cell is formed by a symmetrical comb shaped strips (resonator) place on either side with a split gap between them. The resonators form the inductive effect and the split gaps form the capacitive effect as shown in the equivalent circuit Figure 3a. With the help of such structure this unit cell can operate at 2.9 and $3.9 \mathrm{GHz}$. The operation of this multiband behavior can be understood by studying the reflection ( $|S 11|$ ) and transmission ( $|S 21|$ ) coefficient (i.e., pass band behavior) by placing the unit cell in waveguide medium. This study is based on Nicholson-Ross-Weir (NRW) technique which was further elaborated by Smith et al. [21] to extract the material parameters utilizing waveguide medium theory. The waveguide environment is used 
to calculate the value of IS11 I and IS21 I of the proposed metamaterial unit cell CSSRR. The CSSRR is placed inside the waveguide environment where it is provided with Perfect Electric Conductor (PEC) and Perfect Magnetic Conductor (PMC) boundary conditions. The electromagnetic wave is provided at port 1 (i.e., input port) and the complex value of IS11 I and IS21 I are calculated using output port 2, as demonstrated in Figure 3b, wherein one can see that the stop band phenomenon is observed at 2.9 and $3.9 \mathrm{GHz}$ (Since at this operating frequency IS21 I is less than $10 \mathrm{~dB}$ and IS11| is closer to zero). Subsequently, the effective permeability ( $\left.\mu_{e f f}\right)$ is calculated using [2] and is demonstrated in Figure 3c.

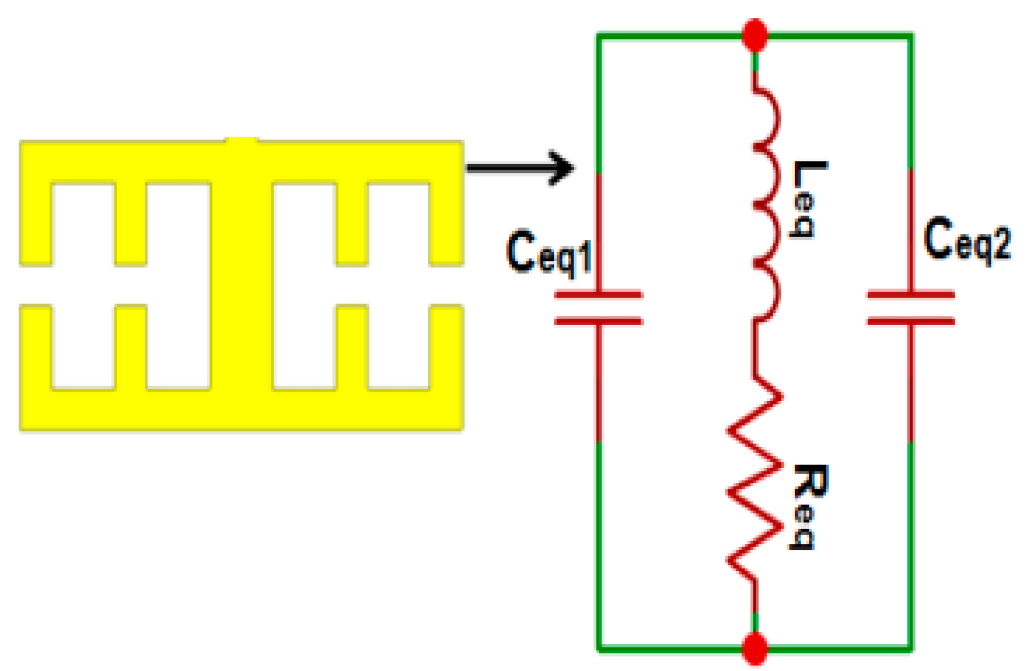

(a)

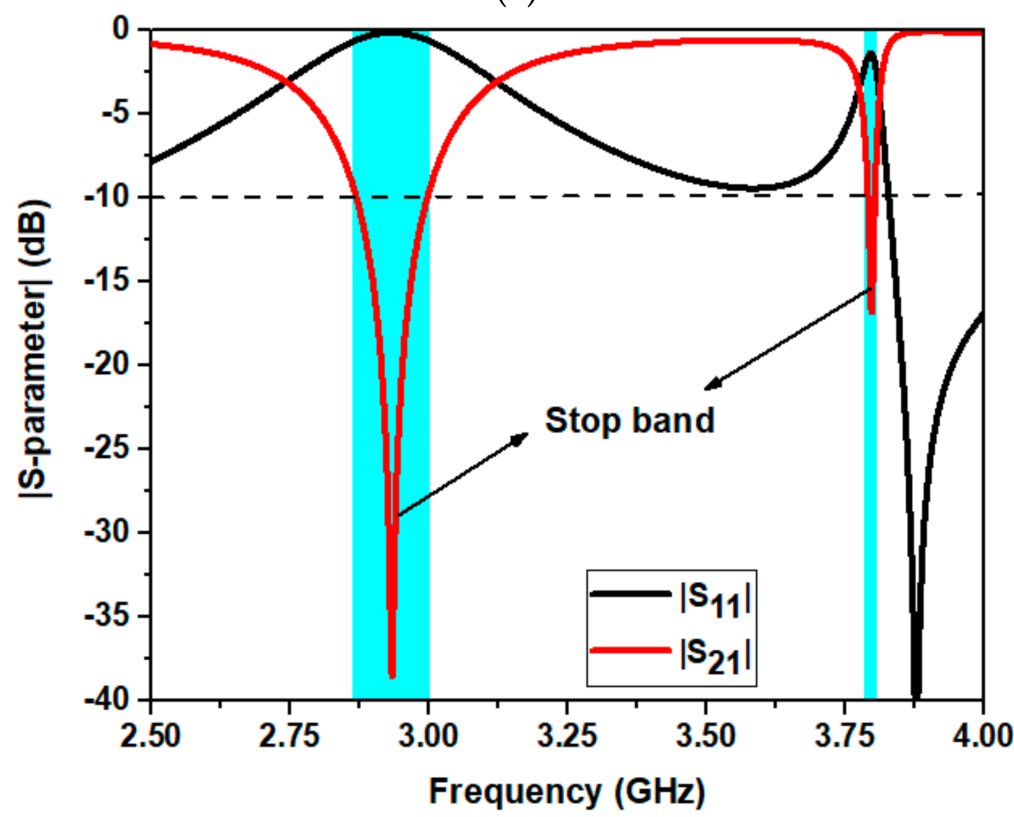

(b)

Figure 3. Cont. 


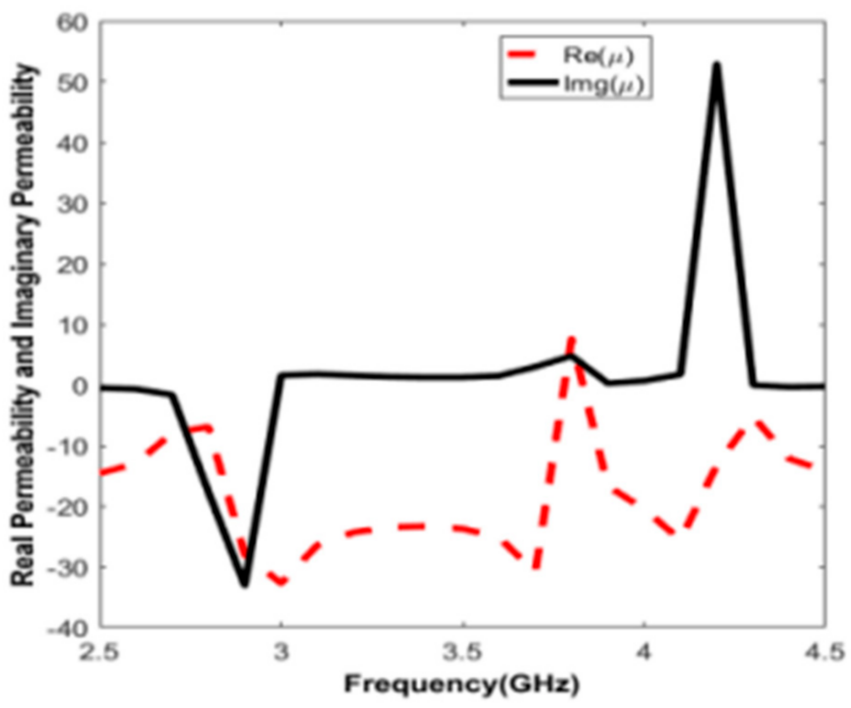

(c)

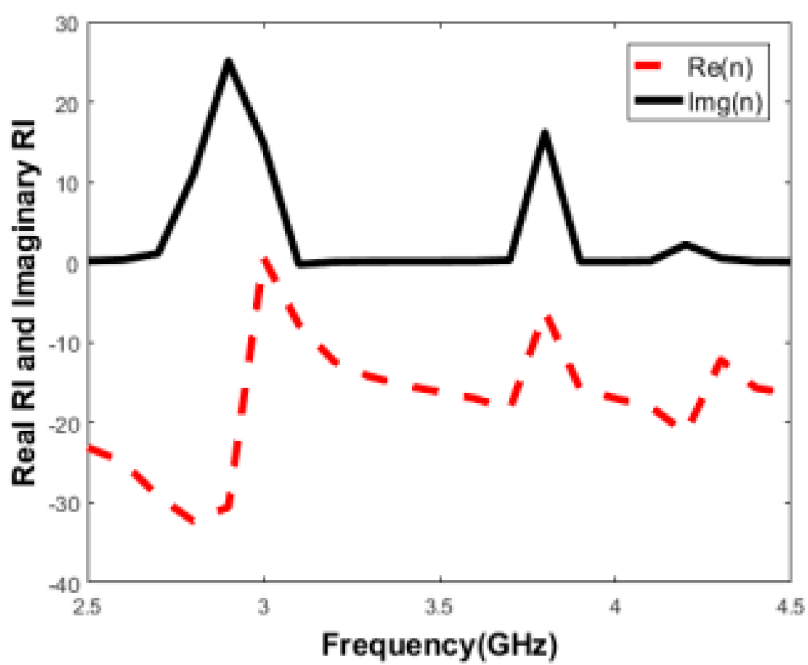

(d)

Figure 3. Metamaterial CSSRR analysis (a) Proposed CSSRR with its equivalent circuit (b) ISparameter I obtained from waveguide medium (c) Real and imaginary effective permeability $\left(\mu_{e f f}\right)$ and (d) Real and imaginary effective refractive index $\left(\eta_{\text {eff }}\right)$ of the CSSRR.

The CSSRR resonant frequency is computed as given in (1).

$$
\omega_{r}=\frac{1}{\sqrt{L_{e q} C_{e q}}}
$$

where $L_{e q}$, signifies the total inductance due to the metallic ring whereas $C_{e q}$ denotes the total capacitance $\left(C_{e q 1}|| C_{e q 2}\right)$ of the split gap of CSSRR as represented in equivalent circuit (Figure 3a). Accordingly, the effective permeability $\left(\mu_{\text {eff }}\right)$, impedance $\left(Z_{\text {eff }}\right)$ and refractive index $\left(\eta_{e f f}\right)$ are computed from the $S$ parameters using Equations (2)-(4) [21].

$$
\mu_{e f f}=n_{e f f} \times Z_{e f f}
$$

where,

$$
Z_{e f f}=\sqrt{\frac{\left(1+S_{11}\right)^{2}-S_{21}{ }^{2}}{\left(1-S_{11}\right)^{2}-S_{21}{ }^{2}}}
$$


The convention of impedance is determined by imposing the conditions $\left.\operatorname{Re}\left(Z_{e f f}\right)\right)$ and $\operatorname{Im}\left(\eta_{e f f}\right)$ as given in $[22,23]$.

$$
n_{e f f}=\frac{1}{k_{0} d}\left\{\operatorname{Im}\left[\ln \left(e^{i n k_{0} d}\right)\right]+2 m \pi-i \operatorname{Re}\left[\ln \left(e^{i n k_{0} d}\right)\right]\right\}
$$

where,

$$
e^{i n k_{0} d}=\frac{S_{21}}{1-S_{11}\left(\frac{z-1}{z+1}\right)}
$$

$k_{0}=\frac{2 \pi f}{c}$, corresponds to speed of light measured in $\mathrm{m} / \mathrm{s}, f$ denotes the operating frequency, the branch index is denoted as $\mathrm{m}$ and the thickness of the substrate is given by d. The extracted $\mu_{\text {eff }}$ and $\eta_{\text {eff }}$ is illustrated in Figure 3c,d. Henceforth, it is observed that a negative value of permeability for the real part is observed at 2.9 and $3.9 \mathrm{GHz}$, this is due to the effect of stopband phenomenon of this CSSRR. This negative value for permeability implies when the structure is used as a radiator, the antenna exhibits new frequency in terms of return loss characteristics.

Similar to this analysis, the SCSRR analysis was conducted and the negative permeability is observed at $5.9 \mathrm{GHz}$. For brevity we have not included the analysis here.

\section{Split Gap Analysis, Individual Unit Cell (Resonator) Loading Effect, and Current Distribution}

To fix the size of both the metamaterial split gaps its parametric investigation is carried out and is explained in Figure 4. These parametric investigations provide an optimized dimension of the design of metamaterial antenna. It can be analyzed from Figure $4 \mathrm{a}$ that an alteration in the spilt gap width in CSSRR $\left(S_{R}\right)$ the impedance matching at all the three band is affected. At $S_{R}=0.5 \mathrm{~mm}$, the antenna becomes dual band as the $|\mathrm{S} 11|$ value at first resonance shifts above $-10 \mathrm{~dB}$. At $S_{\mathrm{R}}=1.5 \mathrm{~mm}$, a shift at fundamental mode is observed, decrease in the value of $|S 11|$ is observed at second mode, while there is no change observed at the third mode. For the proper operation of antenna at all the three frequency the dimension of $S_{R}$ is fixed at $1.5 \mathrm{~mm}$.

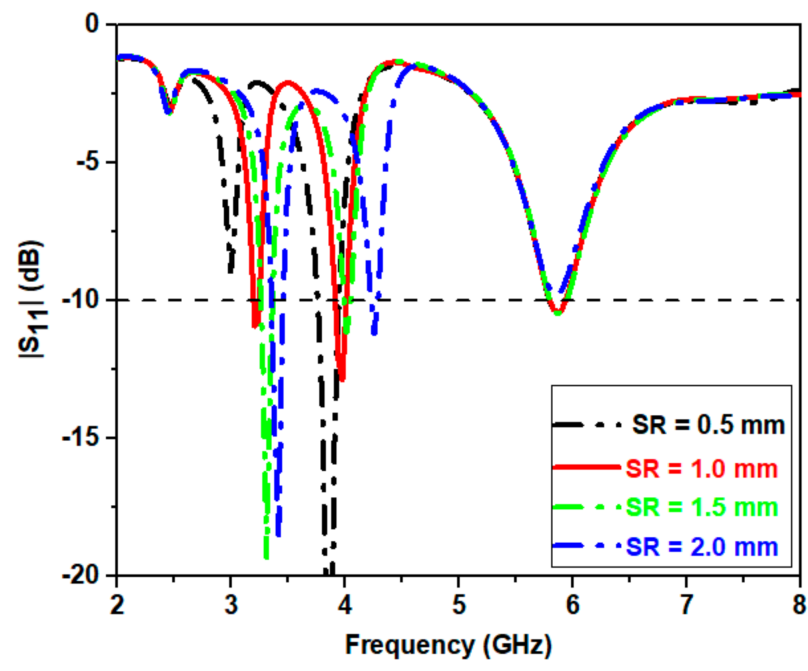

(a)

Figure 4. Cont. 


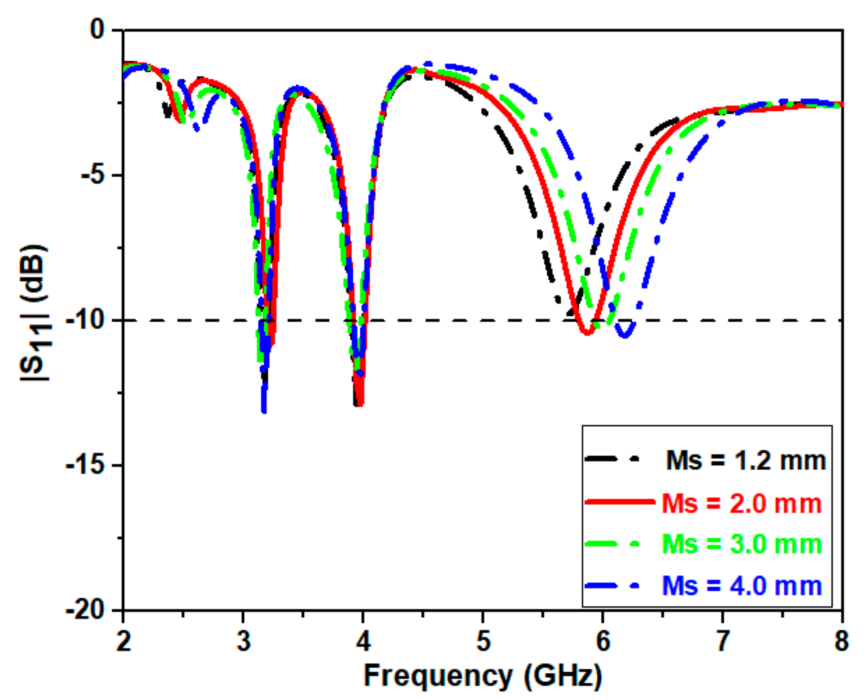

(b)

Figure 4. Variation of SR on (a) $S_{11}$ and (b) $M_{S}$.

Similarly, the split gap $\left(\mathrm{M}_{\mathrm{S}}\right)$ analysis of the second unit cell SCSRR is carried out and is displayed in Figure $4 \mathrm{~b}$. It can be studied that at $\mathrm{M}_{\mathrm{S}}=1.2 \mathrm{~mm}, 3 \mathrm{~mm}$ and $4 \mathrm{~mm}$, the first two modes are least affected while there is a noticeable resonance shift at third mode. For proper operation of antenna at all the three frequency the dimension of $M_{S}$ is fixed at $2 \mathrm{~mm}$. Thus, from this analysis it can be concluded that the spilt gap width in CSSRR $\left(S_{R}\right)$ and SCSRR $\left(M_{S}\right)$ perturbs the surface current distribution, which drastically affects the resonance and impedance behavior of the antenna.

To understand the loading effect of each unit cell individually and to analyze how each resonance is impacted by the other one as a parasitic element, a study is carried out and is depicted in Figure 5. From the figure it is noted that when the unit cell SCSRR is loaded individually, a narrow resonance is observed at $5.8 \mathrm{GHz}$. When only the unit cell CSSRR is loaded it shows single band operation around $4 \mathrm{GHz}$. When both the unit cells are loaded together antenna shows triple band operation (i.e., 3.2, 4 and $5.9 \mathrm{GHz}$ ), which is basically due to parasitic loading effect of both the unit cell simultaneously which affect the flow of surface current distribution, thereby making the antenna exhibit multiband behavior.

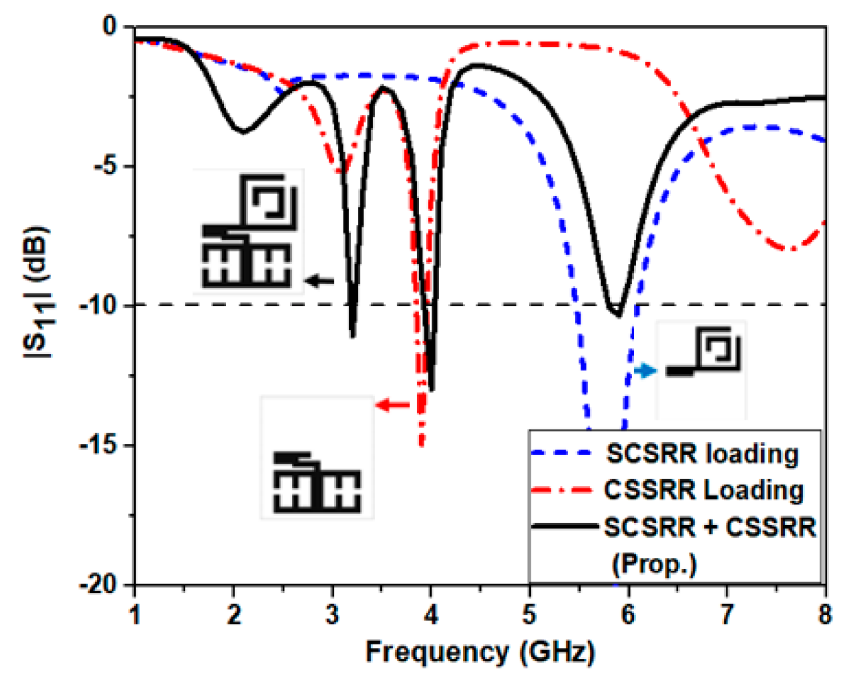

Figure 5. Effect of loading individual metamaterial unit cell. 
The current operation of this multiband antenna is illustrated in Figure 6. It can be visualized that the current distribution in the antenna resonant path varies for each of the operating modes.

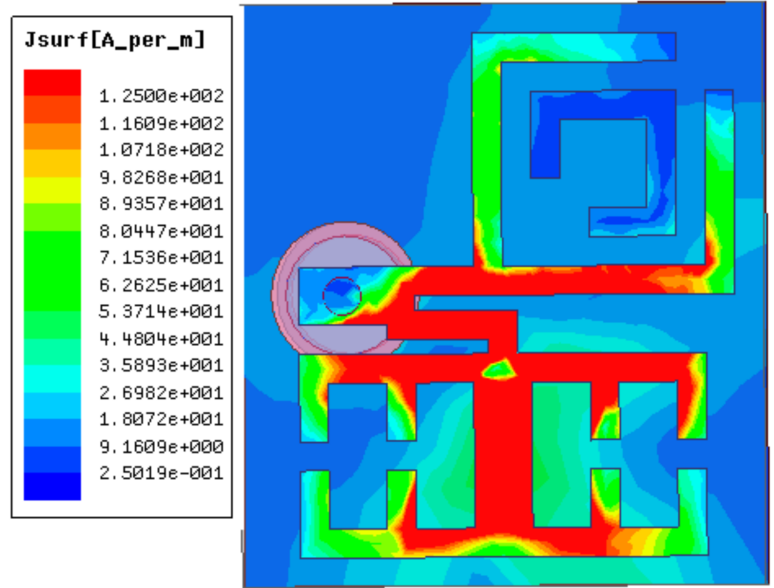

(a)

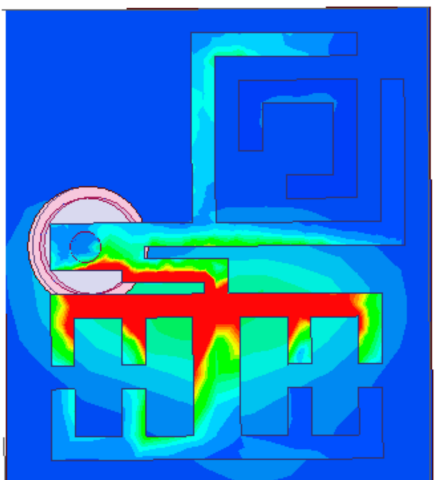

(b)

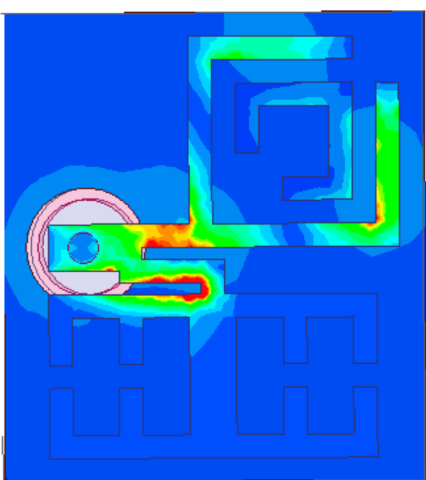

(c)

Figure 6. Surface current distributions at (a) $3.2 \mathrm{GHz}$, (b) $4 \mathrm{GHz}$, and (c) $5.9 \mathrm{GHz}$.

\section{Results and Discussion}

The model of this fabricated antenna is demonstrated in Figure 7a. This model is fabricated using the photographic etching procedure. The block diagram to measure $\left|S_{11}\right|$ of the antenna from vector network analyzer is illustrated in Figure $7 \mathrm{~b}$. The $\left|\mathrm{S}_{11}\right|$ of the antenna is measured using two port network analyzers, wherein at one port the antenna is kept and its readings are observed. The port 2 is terminated to a perfect matching load of $50 \mathrm{ohms}$. The compared simulated and measured $\left|S_{11}\right|$ results of the said antenna are described in Figure 7c. The antenna shows operation at 3.2 (WiMAX), 4 and $5.9 \mathrm{GHz}$ under simulation with $\left|S_{11}\right|<-10 \mathrm{~dB}$ bandwidth of about $3.12 \%, 2.5 \%$ and $2.54 \%$. In the measurement, the antenna shows operation at $2.9,3.9$ and $5.8 \mathrm{GHz}$ with $\left|\mathrm{S}_{11}\right|<-10 \mathrm{~dB}$ bandwidth of about $3.39 \%, 3.11 \%$ and $9.28 \%$. It is observed that there is a good correlation between the measured and simulated results. 


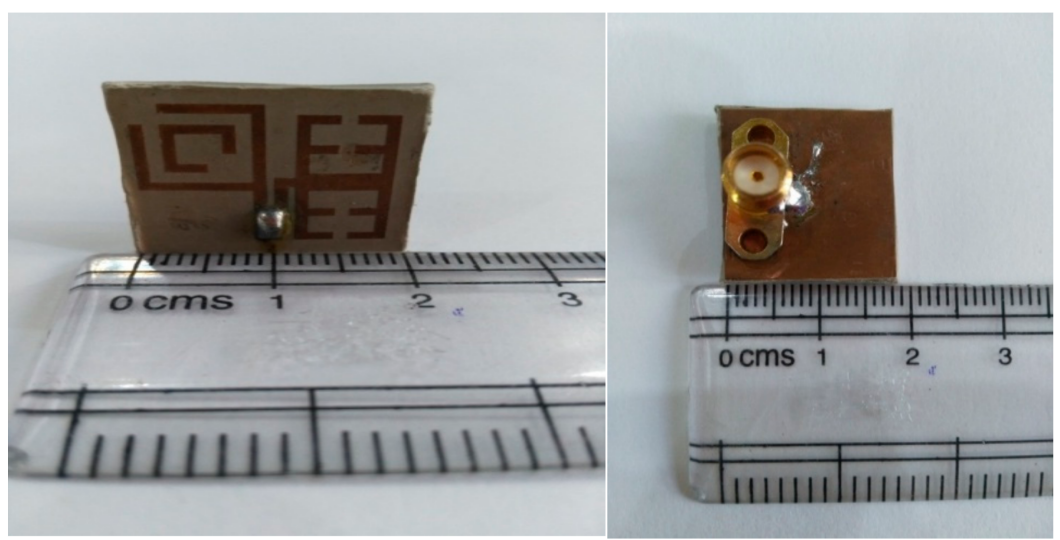

(a)

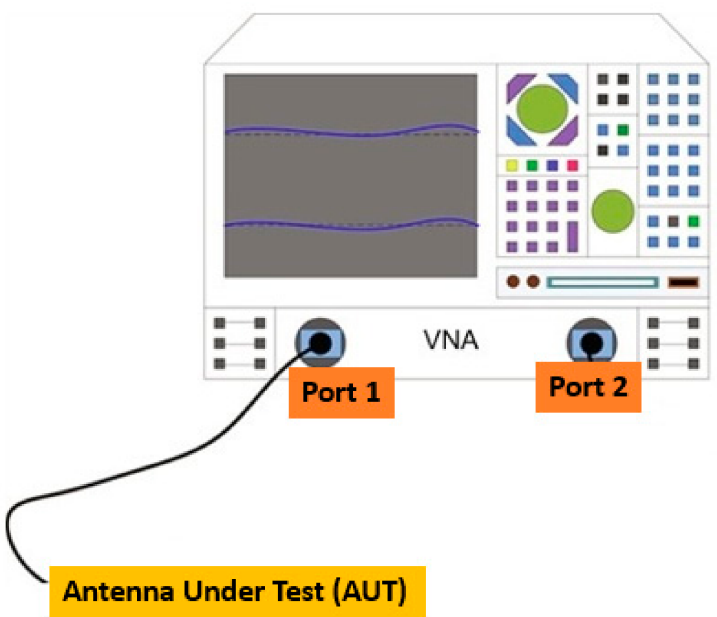

(b)

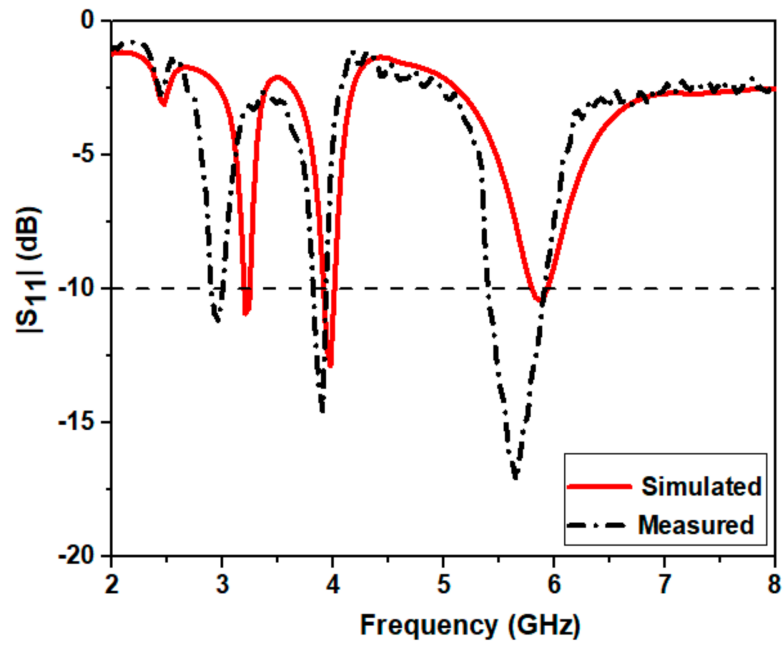

(c)

Figure 7. Proposed configuration (a) fabricated model (b) Schematic diagram of Vector Network Analyzer (VNA) to measure $\left|S_{11}\right|$ of the antenna and (c) compared simulated and measured $\left|S_{11}\right|$.

The simulated radiation pattern of the antenna in the $\mathrm{E}$ and $\mathrm{H}$ planes are depicted in Figure 8. It can be seen that the antenna exhibits stable radiation pattern in both the plane. Moreover, the antenna shows dipole like stable radiation patterns (i.e., H-plane omnidirectional and E-plane dumbbell shaped) which is best suited for the aforementioned applications. 


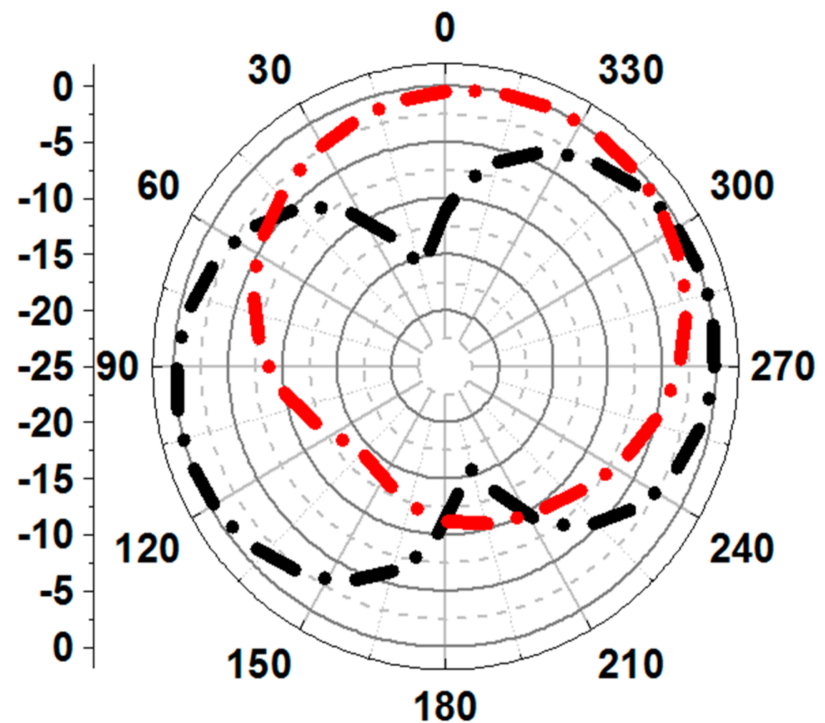

(a)

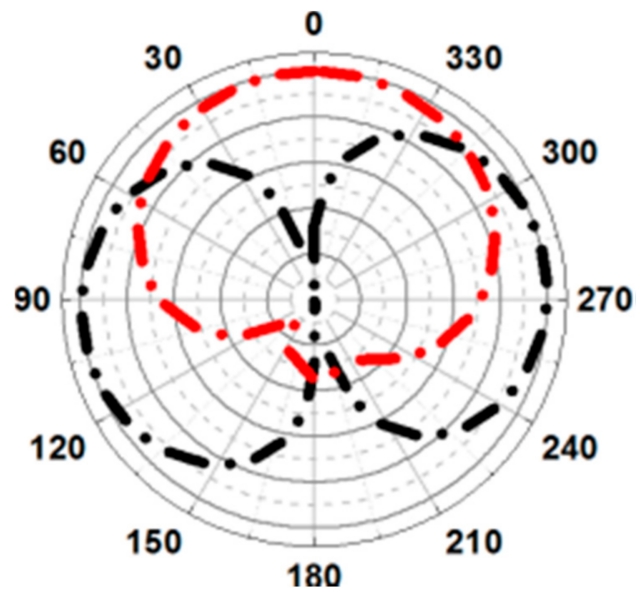

(b)

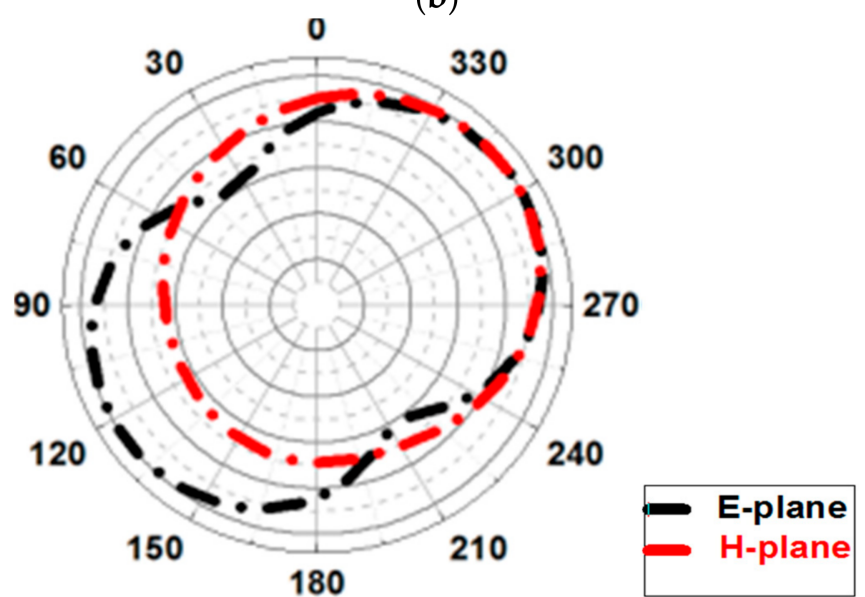

(c)

Figure 8. Simulated radiation patterns at (a) $3.2 \mathrm{GHz}$ (b) $4 \mathrm{GHz}$ (c) $5.9 \mathrm{GHz}$.

The simulated radiation efficiency of the antenna is represented in Figure 9. This antenna exhibits an efficiency of $87 \%, 90 \%$, and $98 \%$ at $3.2,4.0$, and $5.9 \mathrm{GHz}$, respectively. 


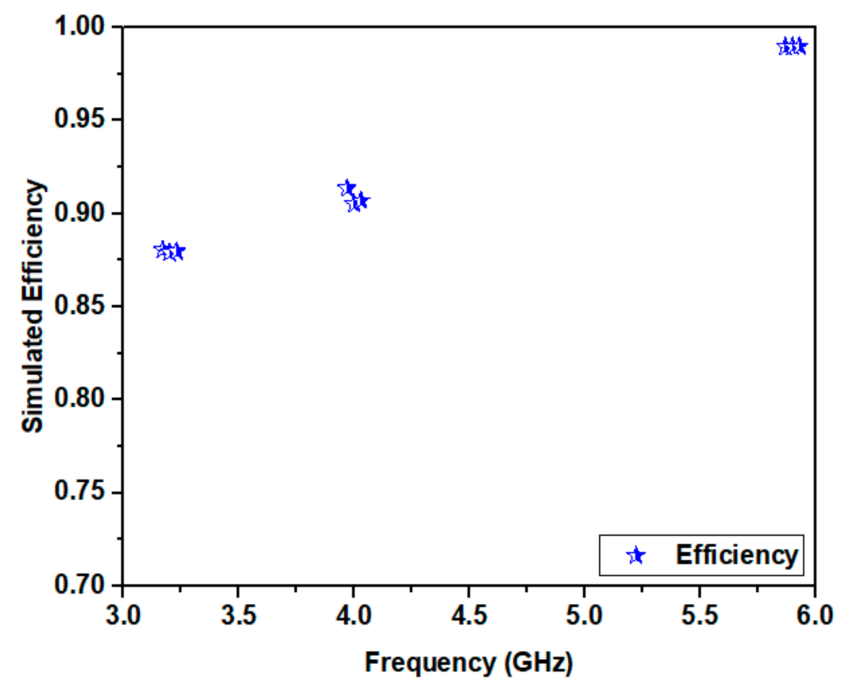

Figure 9. Proposed configuration simulated radiation efficiency.

Table 2 provides a comparative analysis of miniaturized multiband antenna proposed in the current work and with those investigated in the literature. It can be observed from Table 2 that the design proposed in this current paper gives a better insight when compared to the work in open literature in terms of size, multiband operation, and design complexity.

Table 2. Comparative analysis of the proposed design.

\begin{tabular}{|c|c|c|c|c|c|}
\hline Ref. & Size $\left(\mathrm{mm}^{2}\right)$ & $\begin{array}{l}\text { Operating Bands } \\
\text { (GHz) }\end{array}$ & $\begin{array}{l}\text { Metamaterial } \\
\text { Structure }\end{array}$ & Antenna Design Technique & $\begin{array}{c}\text { Metamaterial } \\
\text { Property Verified }\end{array}$ \\
\hline [15] & $40 \times 45$ & $2.44 / 3.5 / 5.5$ & Rectangular stub & $\begin{array}{l}\text { Monopole with inverted L-shaped } \\
\text { slot as the radiating plane and } \\
\text { partial ground plane with thin } \\
\text { inductive stub loaded with } \\
\text { rectangular patch }\end{array}$ & No \\
\hline [17] & $20 \times 22$ & $2.48 / 3.49$ & SRR & $\begin{array}{c}\text { Meandered line square shaped SRR } \\
\text { monopole fed with asymmetric } \\
\text { CPW }\end{array}$ & No \\
\hline [18] & $30 \times 20$ & 5.63 & CSRR & Patch loaded with two CSRR & No \\
\hline [19] & $30 \times 40$ & 2.4 & CSRR & $\begin{array}{l}\text { Rectangular patch with loaded } \\
\text { CSRR on front and ground part }\end{array}$ & No \\
\hline [20] & $42 \times 50$ & $1.8 / 5.2$ & $\begin{array}{l}\text { three zeroth order } \\
\text { resonator }(\mathrm{ZOR}) \text { cells }\end{array}$ & $\begin{array}{l}\text { Rectangular patch with } \\
\text { L-shaped ground }\end{array}$ & No \\
\hline [24] & $23 \times 26$ & $2.5 / 3.6 / 5.8$ & $\begin{array}{l}\text { Triangular shaped } \\
\text { split ring resonator }\end{array}$ & $\begin{array}{l}\text { Strip line electrically coupled with } \\
\text { metamaterial unit cell on either side }\end{array}$ & Yes \\
\hline [25] & $50 \times 40$ & $2.4 / 3.5 / 5.8$ & SRR & $\begin{array}{l}\text { Two pair of symmetrical SRR with } \\
\text { the initial monopole on the front } \\
\text { side }\end{array}$ & Yes \\
\hline [26] & $40 \times 12$ & $2.5 / 3.5$ & $\begin{array}{l}\text { Stepped Impedance } \\
\text { closed ring resonator } \\
\text { (SICRR) }\end{array}$ & $\begin{array}{l}\text { Rectangular patch with partial } \\
\text { ground plane }\end{array}$ & No \\
\hline [27] & $20 \times 30$ & $2.1 / 7.3$ & CRLH unit cell & $\begin{array}{l}\text { Annular resonator with partial } \\
\text { ground plane }\end{array}$ & No \\
\hline
\end{tabular}


Table 2. Cont.

\begin{tabular}{cccccc}
\hline Ref. & Size $\left(\mathbf{m m}^{2}\right)$ & $\begin{array}{c}\text { Operating Bands } \\
\mathbf{( G H z )}\end{array}$ & $\begin{array}{c}\text { Metamaterial } \\
\text { Structure }\end{array}$ & Antenna Design Technique & $\begin{array}{c}\text { Metamaterial } \\
\text { Property Verified }\end{array}$ \\
\hline$[28]$ & $28 \times 21$ & $2.4 / 5.2$ & $\begin{array}{c}\text { metamaterial-based } \\
\text { electromagnetic } \\
\text { bandgap } \\
(\text { MTM-EBG })\end{array}$ & $\begin{array}{c}\text { Rectangular patch with EBG at } \\
\text { the edges }\end{array}$ & Yes \\
\hline$[29]$ & $20 \times 30$ & $1.2 / 6.0$ & ZOR unit cell & $\begin{array}{c}\text { Monopole antenna loaded with } \\
\text { series inductor and capacitor }\end{array}$ & No \\
\hline Prop. & $20 \times 18$ & $3.2 / 4 / 5.9$ & CSSRR and SCSRR & $\begin{array}{c}\text { Rectangular stub loaded CSRRR } \\
\text { and SCSRR as the radiating part } \\
\text { and full ground plane }\end{array}$ & Yes \\
\hline
\end{tabular}

\section{Conclusions}

A new multiband antenna loaded with metamaterial is presented. The major advantage of this proposed design lies in its compact size and simple and planar metamaterial structure which independently controls a particular band by utilizing a particular unit cell. It is shown that the split gaps of the proposed unit cell play a significant role in determining the frequency of resonance. The proposed configuration resonates at triple band with stable radiation characteristics that make it quite attractive for WiMAX and WLAN applications.

Author Contributions: Conceptualization, R.M.D., M.S.A., P.K. and T.A.; Data curation, M.S.A.; Formal analysis, R.M.D., T.A. and P.K.; Investigation, R.M.D., M.S.A. and T.A.; Methodology, R.M.D., M.S.A., T.A. and P.K.; Project administration, T.A.; Resources, M.S.A.; Software, M.S.A.; Supervision, T.A.; Validation, M.S.A.; Visualization, T.A.; Writing—original draft, R.M.D.; Writing—review \& editing, T.A. and P.K. All authors have read and agreed to the published version of the manuscript.

Funding: This research received no external funding.

Institutional Review Board Statement: Not applicable.

Informed Consent Statement: Not applicable.

Data Availability Statement: Not applicable.

Conflicts of Interest: The authors declare no conflict of interest.

\section{References}

1. Dong, Y.; Itoh, T. Metamaterial-Based Antennas. Proc. IEEE 2012, 100, 2271-2285. [CrossRef]

2. Prasad, K.D.; Ali, T.; Biradar, R.C. A compact slotted multiband antenna for L-band and WLAN applications. In Proceedings of the 2017 2nd IEEE International Conference on Recent Trends in Electronics, Information \& Communication Technology (RTEICT), Bangalore, India, 19-20 May 2017; pp. 820-823.

3. Ali, T.; Mohammad, S.A.W.; Biradar, R.C. A novel metamaterial rectangular CSRR with pass band characteristics at 2.95 and $5.23 \mathrm{GHz}$. In Proceedings of the 2017 2nd IEEE International Conference on Recent Trends in Electronics, Information \& Communication Technology (RTEICT), Bangalore, India, 19-20 May 2017; pp. 256-260.

4. Ali, T.; Subhash, B.K.; Pathan, S.; Biradar, R.C. A compact decagonal-shaped UWB monopole planar antenna with truncated ground plane. Microw. Opt. Technol. Lett. 2018, 60, 2937-2944. [CrossRef]

5. Grimberg, R. Electromagnetic metamaterials. Mater. Sci. Eng. B 2013, 178, 1285-1295. [CrossRef]

6. Veselago, V.G. The Electrodynamics of Substances with Simultaneously Negative Values of $\epsilon$ and $\mu$. Phys. Uspekhi 1968, 10, 509-514. [CrossRef]

7. Pendry, J.B. Negative Refraction Makes a Perfect Lens. Phys. Rev. Lett. 2000, 85, 3966-3969. [CrossRef] [PubMed]

8. Caloz, C.; Itoh, T. Electromagnetic Metamaterials: Transmission Line Theory and Microwave Applications; John Wiley \& Sons: Hoboken, NJ, USA, 2005.

9. Krzysztofik, W.J.; Cao, T.N. Metamaterials in application to improve antenna parameters. In Metamaterials and Metasurfaces; IntechOpen: London, UK, 2018.

10. Pouyanfar, N.; Nourinia, J.; Ghobadi, C.; Pedram, K. Compact Multiband Metamaterial-Based Antenna for WLAN and WiMAX Applications. In Proceedings of the 2019 5th Conference on Knowledge Based Engineering and Innovation (KBEI), Tehran, Iran, 28 February-1 March 2019; pp. 250-255. 
11. Choudhury, B. Metamaterial Inspired Electromagnetic Applications; Springer Nature: London, UK, 2017.

12. Haider, A.; Khan, T.; Rahman, M.; Lee, B.M.; Kim, H.S. Quintuple Band Antenna for Wireless Applications with Small Form Factor. Comput. Mater. Contin. 2021, 66, 2241-2251. [CrossRef]

13. Khan, T.; Rahman, M. Design of Low-Profile Frequency Reconfigurable Antenna for Multiband Applications. Int. J. Electron. Lett. 2020, 1-18. [CrossRef]

14. Amani, N.; Kamyab, M.; Jafargholi, A.; Hosseinbeig, A.; Meiguni, J.S. Compact tri-band metamaterial-inspired antenna based on CRLH resonant structures. Electron. Lett. 2014, 50, 847-848. [CrossRef]

15. Huang, H.; Liu, Y.; Zhang, S.; Gong, S. Multiband Metamaterial-Loaded Monopole Antenna for WLAN/WiMAX Applications. IEEE Antennas Wirel. Propag. Lett. 2014, 14, 662-665. [CrossRef]

16. Yu, K.; Li, Y.; Wang, Y. Multi-band metamaterial-based microstrip antenna for WLAN and WiMAX applications. In Proceedings of the 2017 International Applied Computational Electromagnetics Society Symposium-Italy (ACES), Florence, Italy, 26-30 March 2017; pp. 1-2.

17. Naik, K.K. Asymmetric CPW-fed SRR patch antenna for WLAN/WiMAX applications. AEU Int. J. Electron. Commun. 2018, 93, 103-108. [CrossRef]

18. Aznabet, M.; El Mrabet, O.; Floc'H, J.M.; Falcone, F.; Drissi, M. A coplanar waveguide-fed printed antenna with complementary split ring resonator for wireless communication systems. Waves Random Complex Media 2014, 25, 43-51. [CrossRef]

19. Geetharamani, G.; Aathmanesan, T. Design of Metamaterial Antenna for $2.4 \mathrm{GHz}$ WiFi Applications. Wirel. Pers. Commun. 2020 113, 2289-2300. [CrossRef]

20. Tran, T.Q.; Kim, S. Ultracompact Si slot waveguide-based polarization rotators. Microw. Opt. Technol. Lett. 2015, 57, 779-785. [CrossRef]

21. Smith, D.R.; Vier, D.C.; Koschny, T.; Soukoulis, C.M. Electromagnetic parameter retrieval from inhomogeneous metamaterials. Phys. Rev. E 2005, 71, 036617. [CrossRef] [PubMed]

22. Szabo, Z.; Park, G.H.; Hedge, R.; Li, E.P. A unique extraction of metamaterial parameters based on Kramers-Kronig relationship. IEEE Trans. Microw. Theory Tech. 2010, 58, 2646-2653. [CrossRef]

23. Chen, X.; Grzegorczyk, T.M.; Wu, B.-I.; Pacheco, J.J.; Kong, J.A. Robust method to retrieve the constitutive effective parameters of metamaterials. Phys. Rev. E 2004, 70, 016608. [CrossRef] [PubMed]

24. Mouhouche, F.; Azrar, A.; Dehmas, M.; Djafri, K. A Compact Multi-Band Monopole Antenna using Metamaterial for WLAN/WiMAX Applications. Adv. Electromagn. 2019, 8, 92-98. [CrossRef]

25. Kim, D.O.; Kim, C.-Y.; Yang, D.-G.; Ahmad, M.S. Multiband omnidirectional planar monopole antenna with two split ring resonator pairs. Microw. Opt. Technol. Lett. 2017, 59, 753-758. [CrossRef]

26. Sharma, S.K.; Abdalla, M.; Chaudhary, R.K. An electrically small sicrr metamaterial-inspired dual-band antenna for WLAN and WiMAX applications. Microw. Opt. Technol. Lett. 2017, 59, 573-578. [CrossRef]

27. Gupta, A.; Chaudhary, R.K. A compact dual band short ended metamaterial antenna with extended bandwidth. Int. J. RF Microw. Comput. Eng. 2016, 26, 435-441. [CrossRef]

28. Smyth, B.P.; Barth, S.; Iyer, A.K. Dual-Band Microstrip Patch Antenna Using Integrated Uniplanar Metamaterial-Based EBGs. IEEE Trans. Antennas Propag. 2016, 64, 5046-5053. [CrossRef]

29. Sonak, R.; Ameen, M.; Chaudhary, R.K. CPW-fed electrically small open-ended zeroth order resonating metamaterial antenna with dual-band features for GPS/WiMAX/WLAN applications. AEU Int. J. Electron. Commun. 2019, 104, 99-107. [CrossRef] 